\title{
IDENTIFICATION OF BONDED CLAY PARAMETERS IN SBPM TESTS: A NUMERICAL STUDY
}

\author{
Nubia Aurora GonzÁlez ${ }^{1)}$, Marcos Arroyoii) and Antonio Gensiii)
}

\begin{abstract}
A bonded elasto-plastic soil model is adopted to simulate self-boring pressuremeter tests. Calibration of the model with results from several natural clays identifies a meaningful parameter range for the simulations. Then a systematic sensitivity analysis of the loading SBPM test curve is carried out with an infinite cylindrical cavity analogue, focusing on the variables and parameters that are specific to the bonded material. This analysis reveals that the effects of mechanical overconsolidation and bonding on the pressuremeter loading curves are very similar. Unloading and strainholding phases of the test show a greater capability to separate mechanical overconsolidation from bonding. The limited effects of finite pressuremeter length and partial drainage on the simulated curves do not change those conclusions.
\end{abstract}

Key words: bonded soils, elasto-plasticity, numerical modelling, pressuremeter (IGC: C3/E13)

\section{INTRODUCTION}

The inclusion of a measure of structure and bonding in modified elasto-plastic soil models is now widespread. The motivation behind this development is the consistent laboratory observation of important behavioural differences between intact and reconstituted soils when subjected to similar loading paths (e.g., Cotecchia and Chandler, 2000). Such differences appear notwithstanding a common composition, porosity and stress state, and therefore raise the variable(s) embodying structure and/or bonding to the category of basic state variables, on an equal footing with stress and overconsolidation ratio.

Elasto-plastic bonded soil models have proved their capabilities in numerical simulations of laboratory tests (e.g., for clays, Rouainia and Wood, 2000; Kavvaddas and Amorosi, 2000; Baudet and Stallebrass, 2004). Their implementation into finite element codes is also well advanced. However, their general application to engineering problems is still hampered by their seemingly laborious calibration and initialization procedures.

The number of parameters and state variables describing soil behaviour in elasto-plastic bonded soil models is relatively high. An exclusively laboratory-based approach to characterization would be highly demanding in terms of sample quantity and quality. In-situ testing alone seems even more problematic, because erroneous estimations are likely when many parameters are simultaneously sought (e.g., Rangeard et al., 2004). A way out of this difficulty lies in the systematic combination of "in situ" and laboratory tests.

Such an approach is clearly implicit in the bonded elasto-plasticity modeling framework. Parameters describing reconstituted behaviour (critical state friction angle, oedometric compressibility ...) are more easily identified in the laboratory. On the other hand, variables defining "in situ" state and parameters characterizing bonded behaviour would be advantageously profiled by in situ tests.

In this respect it is necessary to establish the most adequate in situ test procedures. Since soil structure is fragile, the measurement methods most suitable for its determination would be that involving minimal soil disturbance. The self boring pressuremeter (SBPM) is widely regarded as the mechanical in-situ test that best preserves undisturbed conditions. This makes it, in principle, a good candidate for structure determination.

In this paper, a bonded elasto-plastic model is employed in a series of numerical simulations of SBPM tests, with the aim of identifying the effects of structure related parameters and variables on test results. The constitutive and numerical model employed is first described, and then a parametric analysis of the loading curve of the SBPM is made. Afterwards cyclic and strain holding phases of the test are also analyzed and finally, a check is made on the likely amount of signal-masking noise due to partial drainage or finite length effects.

\section{MATERIAL MODEL}

The material model is now briefly presented and more

i) Doctoral Student, Department of Geotechnical Engineering and Geosciences, UPC, Spain (nubia.aurora.gonzalez@upc.edu).

ii) Research Assistant, ditto.

iii) Professor, ditto.

The manuscript for this paper was received for review on February 15, 2008; approved on January 29, 2009.

Written discussions on this paper should be submitted before January 1, 2010 to the Japanese Geotechnical Society, 4-38-2, Sengoku, Bunkyo-ku, Tokyo 112-0011, Japan. Upon request the closing date may be extended one month. 


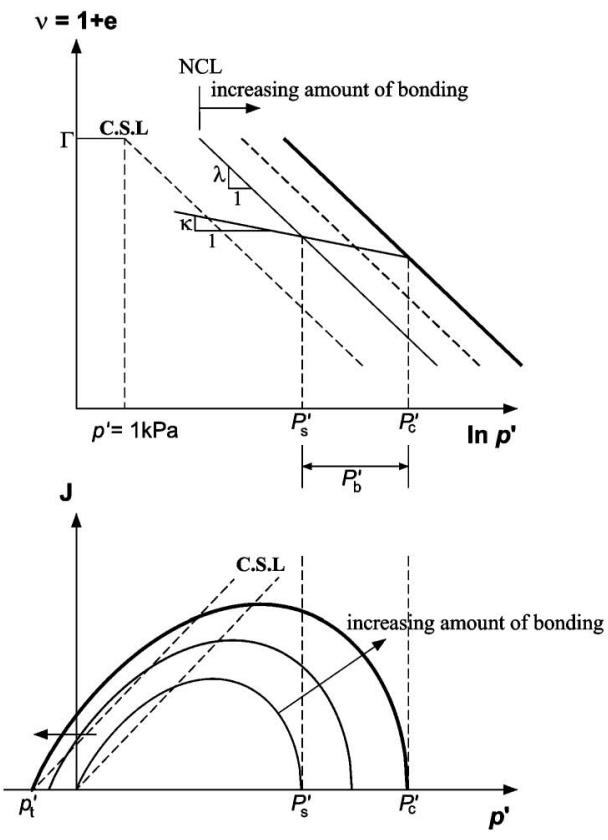

Fig. 1. The normal consolidation lines (NCL), critical state lines (CSL) and yield surfaces for both unbonded and bonded materials

details can be found in Gonzalez et al. (2007). The bonded elasto-plastic material model employed here is based on the CASM (Clay and Sand Model) developed by $\mathrm{Yu}$ (1998). Note that a somewhat different bonded model also based on the CASM has been published recently by $\mathrm{Yu}$ and Tan (2007).

Here, the CASM has been both simplified and extended. The main simplification introduced is that of assuming associated behaviour. The main extension is that of introducing a new scalar history variable, $b$, representing "bonding".

The way in which this bonding variable enters the model follows closely to the original proposal of Gens and Nova (1993). The yield surface is assumed to enlarge with increasing amount of bonding in the soil. It must grow towards the right to account for the fact that higher mean stress can be applied to the material without causing it to yield. Bonding also imparts the sample with real cohesion and tensile strength and therefore the yield surface is enlarged also towards the left of the stress plot. Figure 1 shows the normal consolidation lines and yield surfaces for both unbonded and bonded materials with various amounts of bonding.

The yield surface can be expressed as follows:

$$
f=\left(\frac{\sqrt{3} J}{M_{\theta}\left(p^{\prime}+p_{\mathrm{t}}^{\prime}\right)}\right)^{\mathrm{n}}+\frac{1}{\ln r} \ln \frac{\left(p^{\prime}+p_{\mathrm{t}}^{\prime}\right)}{P_{\mathrm{c}}^{\prime}}
$$

where, to obtain the behavior shown in Fig. 1,

$$
\begin{aligned}
& P_{\mathrm{c}}^{\prime}=P_{\mathrm{s}}^{\prime}(1+b) \\
& p_{\mathrm{t}}^{\prime}=P_{\mathrm{s}}^{\prime}\left(\alpha_{\mathrm{t}} b\right)
\end{aligned}
$$

Where $p^{\prime}$ and $J$ are the first and second stress invariants, $r$ and $\mathrm{n}$ are the model parameters, and $P_{s}^{\prime}$ is the preconsolidation pressure of the debonded reference material. $P_{\mathrm{c}}^{\prime}$ controls the yielding of the bonded soil in isotropic compression and $p_{\mathrm{t}}^{\prime}$ the cohesion and tensile strength of the material; $\alpha_{\mathrm{t}}$ is a parameter. Debonded (reconstituted) behaviour is recovered when $b$ tends to zero. $M_{\theta}$ is the slope of the critical state line (CSL) expressed as a function of the Lode angle following a proposal by Sheng et al. (2000). It determines the shape of the failure surface in the deviatoric plane.

Differently from the original CASM, but according to Gens and Nova (1993), a combined volumetric and shear hardening law for the unbonded material is included in the model.

$$
\frac{d P_{\mathrm{s}}^{\prime}}{P_{\mathrm{s}}^{\prime}}=\frac{1}{\lambda^{*}-\kappa^{*}}\left[d \varepsilon_{\mathrm{v}}^{\mathrm{p}}+\omega d \varepsilon_{\mathrm{s}}^{\mathrm{p}}\right]
$$

$\lambda^{*}$ and $\kappa^{*}$ are the compression parameters of the reconstituted clay, but referred to $\varepsilon_{\mathrm{v}}: \ln p^{\prime}$ space as in Butterfield (1979) and $\omega$ a model parameter. $d \varepsilon_{v}^{\mathrm{p}}$ and $d \varepsilon_{\mathrm{s}}^{\mathrm{p}}$ are the plastic volumetric strain increment and plastic deviatoric strain increment, respectively.

Bonding (b) decreases exponentially with a plastic strain damage measure $(h)$ :

$$
\begin{aligned}
& b=b_{0} e^{-\left(h-h_{0}\right)} \\
& d h=h_{1}\left|d \varepsilon_{\mathrm{v}}^{\mathrm{p}}\right|+h_{2}\left|d \varepsilon_{\mathrm{s}}^{\mathrm{p}}\right|
\end{aligned}
$$

$b_{0}$ is the value of initial bonding and $h_{0}$ is the degradation threshold (by default is taken as zero). $h_{1}$ and $h_{2}$ are material parameters (greater than zero) defining the degradation rate. Similar, but not altogether equivalent parameters appear in other bonded soil model formulations.

\section{NUMERICAL MODEL}

The bonded soil model described above was implemented in the finite element code PLAXIS Version 8, which has a facility to implement user-defined (UD) soil models. Two different test geometries have been employed (Fig. 2), one in which the SBPM test is assumed analogous to the expansion of an infinite cylindrical cavity, and, in the second one, the finite length of pressuremeter probes is considered. Axial symmetry is adopted in both cases. In order to account for large strains within the plastic zone, the analyses always used the large deformations option included in the code. Triangular 15noded elements were always employed.

For the infinite cylindrical cavity analogue a plane strain condition is considered in the vertical direction. With this assumption, the displacements in the medium are everywhere radial, and the problem is essentially onedimensional. A finite outer radius, equal to 30 times the initial cavity radius $a_{0}$, is employed. This length is sufficient to model the condition of infinite medium for clay materials (Zentar et al., 1998). The influence of mesh refinement was investigated for this model. Inspection of Fig. 3 reveals that, to obtain mesh independent results, more than 110 elements on the radial direction were required.

The finite length pressuremeter analyses were conduct- 
ed for the case of a typical length to diameter ratio $(L / D)$ of 6 . The number of nodes and elements were 3063 and 371 respectively. The mesh was refined near to pressuremeter membrane in regions of the possible high stress gradients. The top and the bottom of boundaries of the mesh were at distance of 25 times the pressuremeter radius $\left(a_{0}\right)$ from the centre-line, and in the radial direction the mesh extended to a distance of 50 times the pressuremeter radius $\left(a_{0}\right)$ (i.e., $a_{0}=0.0416 \mathrm{~m}, 25 a_{0}=1.038 \mathrm{~m}$, $\left.50 a_{0}=2.078 \mathrm{~m}\right)$. Similar mesh sizes were chosen by Fioravante et al. (1994) and Jang et al. (2003) for their coupled analyses of pressuremeter tests.

On the top and the bottom boundaries, displacements in the perpendicular directions were prevented. The pressuremeter was modeled as rigid and extending to infinity above and below the membrane. This achieves the desired effect of preventing inward movement at the pressuremeter boundary. It was also assumed that the pressuremeter is always in contact with the soil; this implies a perfectly rough soil-pressuremeter interface. The center

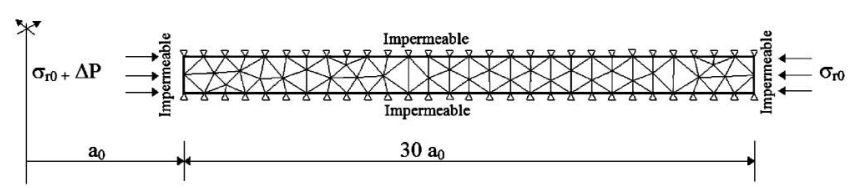

(a)

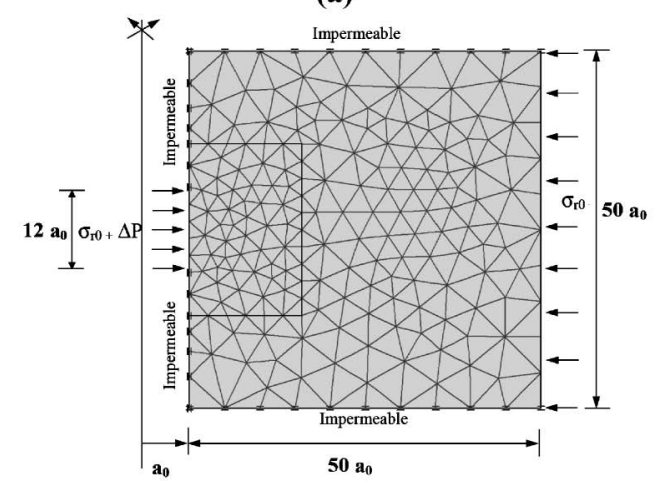

(b)

Fig. 2. Finite element geometry, (a) for infinite cavity expansion cases and (b) for finite-legth pressuremeter cases

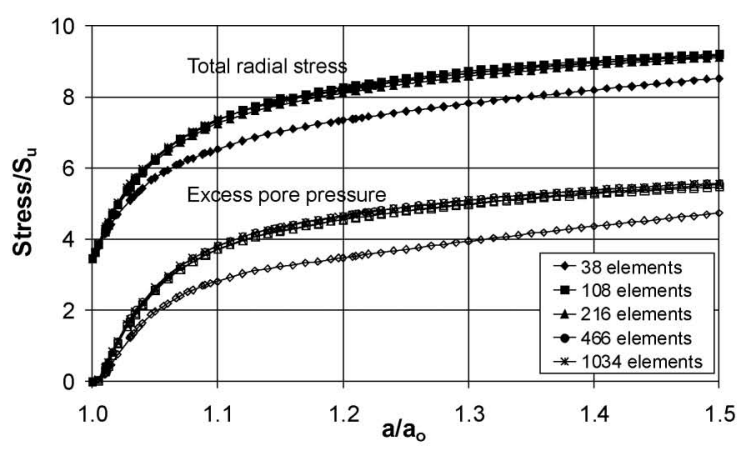

(a) of the pressuremeter membrane was situated at the center of the mesh.

Different drainage conditions were simulated. A perfectly undrained condition is imposed in PLAXIS by adding an equivalent bulk modulus of water to the soil skeleton stiffness. This condition was applied on some simulations with the cylindrical cavity analogue. For such undrained simulations a strain controlled loading procedure was followed. The total radial pressure at the outer boundary was kept constant while the total radial pressure at the cavity wall was increased until the cavity is expanded by $50 \%$ (to a radius of $1.5 a_{0}$ ).

A fully coupled consolidation analysis was employed to allow for a partially drained condition, both in the cavity analogue and in the finite geometry model. A finite, isotropic permeability was assigned to the soil. External boundaries were impermeable. Initial pore pressure was zero, so that effective and total pressures coincide at the start of the simulation. A strain controlled loading procedure was employed. After the geostatic state was initialized, radial expansion of the pressuremeter membrane was simulated using a constant strain rate of $1 \% / \mathrm{min}$, typically used in the field. When the probe was inflated up to the desired cavity strain, a strain holding test was simulated with the strain of the membrane held constant. The development and dissipation of excess pore pressure with time during a whole test processes were checked at the element of the interface corresponding to the mid-height of the membrane, where the pore pressure cell is typically located.

\section{VALIDATION AND CALIBRATION}

The methodology employed was validated against the analytical results for critical state un-bonded soils obtained by Collins and $\mathrm{Yu}$ (1996) and Yu and Collins (1998). The parameters of the yield surface $n$ and $r$ are chosen to approximate the Modified Cam Clay ellipse. The initial bonding parameter $\left(b_{0}\right)$ in Eq. (4) is set to zero and therefore state variable $(b)$ is zero in these simulations. Table 1 collects the other parameters employed, relevant to the London Clay simulated by Collins and

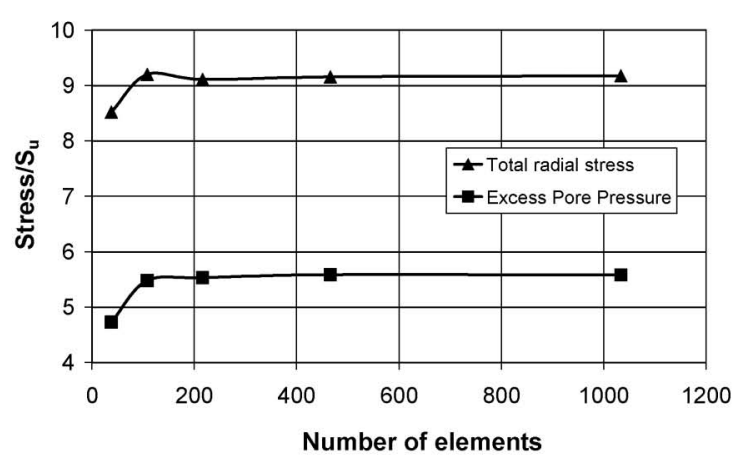

(b)

Fig. 3. Mesh-dependency for the infinite cylindrical cavity analogue, (a) Cavity expansion curves and (b) Limit values obtained at maximum cavity expansion 
$\mathrm{Yu}$. Some of the results of this validation exercise are illustrated in Fig. 4. More details can be found in Gonzalez et al. (2007). A different kind of validation was obtained by the successful simulation of real SBPM results in Bothkennar clay with model parameters inferred from laboratory test (Arroyo et al., 2008).

Table 1. Model parameters for the validation against Collins and Yu (1996)

\begin{tabular}{ccccccccc}
\hline$v$ & $\Gamma$ & $\kappa$ & $\lambda$ & $M$ & $e_{0}$ & $\phi_{\mathrm{cs}}$ & $r$ & $n$ \\
\hline 0.3 & 2.759 & 0.062 & 0.161 & 0.888 & 1.0 & 22.75 & 2 & 1.5 \\
\hline
\end{tabular}

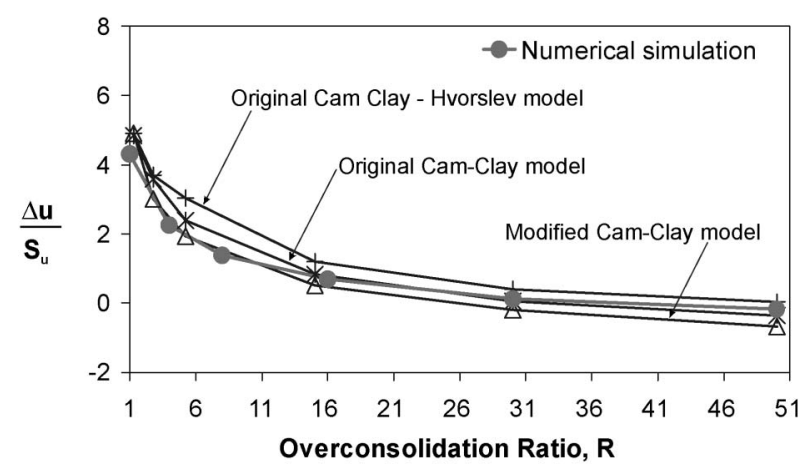

Fig. 4. Variation of the limit normalised excess pore pressure at the cavity wall with $R$. Comparison between numerical simulation and results by Collins and Yu (1996)

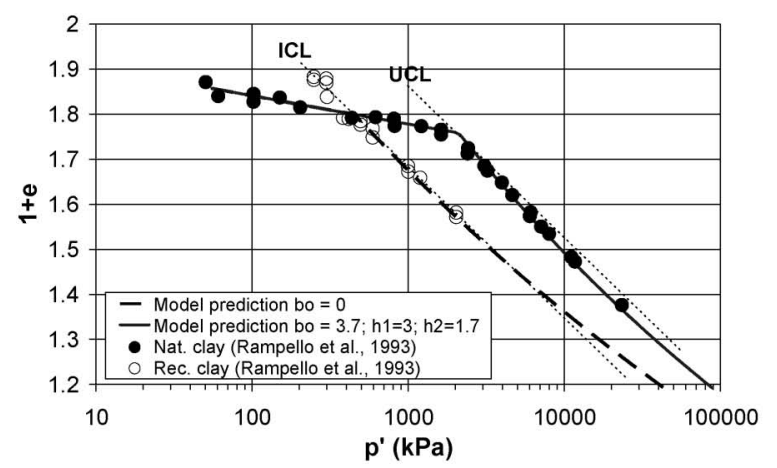

(a)

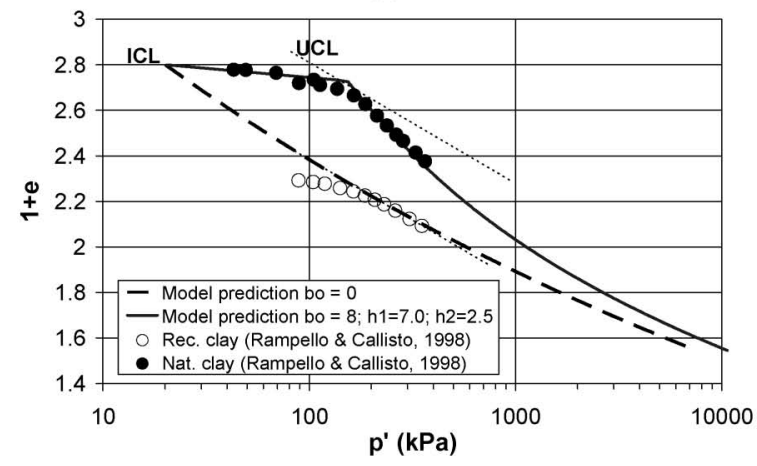

(c)
To narrow the parameter range and increase the relevance of the sensitivity analyses described later, a brief calibration of the model with some structured clay data was done. A summary of the results obtained is presented in Table 2. Figure 5 shows several examples of how these calibrations performed. The fact that all these clays had already been modelled using similar bonded soil models was helpful in speeding the calibration process. The parameters thus obtained were in agreement with an observation by Callisto and Rampello (2004), that plastic volumetric strains give a contribution to structure degradation which is roughly 2 to 3.5 times larger than that produced by plastic deviatoric strains. A fixed ratio of $h_{1} /$

Table 2. Model parameters for some structured clays

\begin{tabular}{l|c|c|c|c|c|c|c|c|c}
\hline \multirow{2}{*}{\multicolumn{1}{c|}{ Clay }} & \multicolumn{3}{|c|}{ Index Properties } & \multicolumn{3}{c|}{$\begin{array}{c}\text { Intrinsic } \\
\text { Properties }\end{array}$} & \multicolumn{3}{c}{$\begin{array}{c}\text { Fitting } \\
\text { Parameters }\end{array}$} \\
\cline { 2 - 11 } & CF \% & LL \% & IP \% & $\lambda$ & $\kappa$ & $P_{s}^{\prime} \mathrm{kPa}$ & $b_{0}$ & $h_{1}$ & $h_{2}$ \\
\hline Vallerica* & 42 & 60.2 & 33.4 & 0.145 & 0.03 & 450 & 3.7 & 3.0 & 1.7 \\
\hline Pietraffita* $^{*}$ & 44 & 87 & 52.5 & 0.208 & 0.02 & 340 & 1.2 & 7.5 & 2.3 \\
\hline Pisa* $^{*}$ & 65 & 80.6 & 49.2 & 0.23 & 0.04 & 20 & 8.0 & 7.0 & 2.5 \\
\hline Bothkennar! $^{*}$ & 36 & 81 & 13 & 0.108 & 0.003 & 12 & 4.0 & 3.0 & \\
\hline Norrkoping $^{+}$ & 62 & 68 & 43 & 0.252 & 0.03 & 40 & .75 & 13.5 & \\
\hline
\end{tabular}

* Callisto and Rampello, 2004

! Cotecchia and Chandler, 2000

${ }^{+}$Rouainia and Muir Wood, 2000

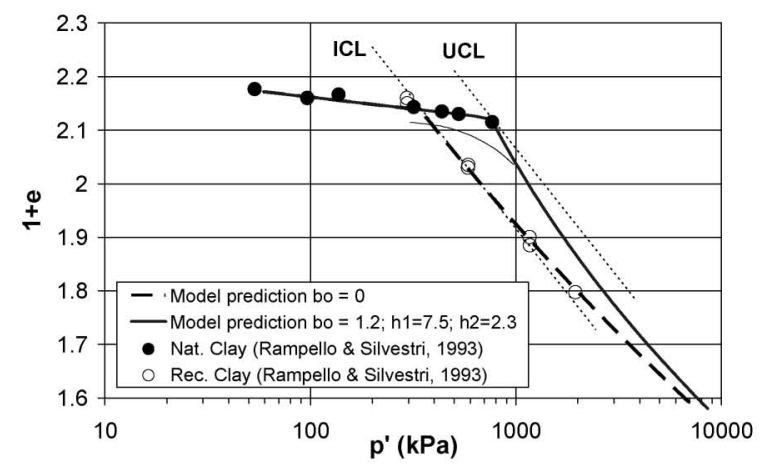

(b)

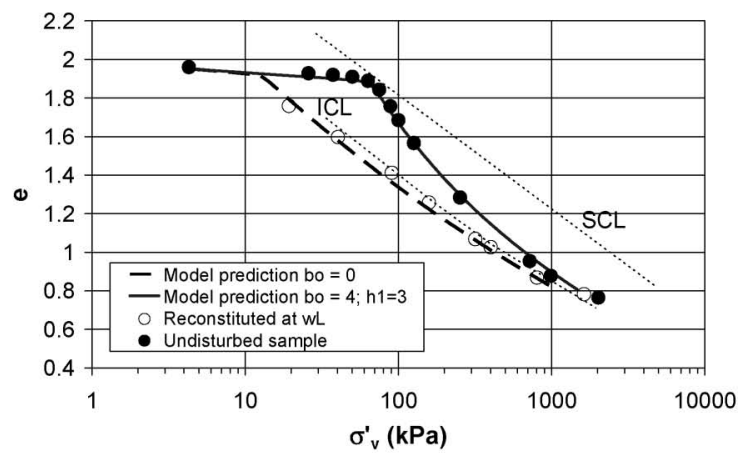

(d)

Fig. 5. Experimental and predicted behaviour in isotropic compression (data from Callisto and Rampello, 2004), (a) for Vallerica clay, (b) for Pietrafitta clay, (c) for Pissa Clay and (d) Oedometer test for Bothkennar clay (data from Cotecchia and Chandler, 2000). ICL, intrinsic compression line; UCL, undisturbed compression line; Nat., natural; Rec., reconstituted; SCL, Secondary compression line 
$h_{2}=3.0$ was then assumed for this study.

\section{PARAMETRIC STUDY OF THE LOADING CURVE}

Using the cylindrical cavity analogue a sensitivity analysis was performed on the SBPM loading curve. Perfectly undrained conditions were assumed. The analysis fixed some parameters (Table 3 ) and exploring the influence of others (Table 4). The focus here is on the influence of initial state and debonding on the simulated response of bonded soils. This explains the choice of the fixed parameters, since all but one $\left(h_{1} / h_{2}\right)$ control the unbond-

Table 3. Fixed parameters for the sensitivity analysis

\begin{tabular}{cccccccc}
\hline$v$ & $N^{\mathrm{a}}$ & $\kappa$ & $\lambda$ & $M$ & $r$ & $n$ & $h_{1} / h_{2}$ \\
\hline 0.3 & 3.0 & 0.03 & 0.20 & 1.113 & 2 & 1.5 & 3 \\
\hline
\end{tabular}

a Specic volume on the NCL for $\mathrm{p}^{\prime}=1 \mathrm{kPa}$

Table 4. Exploratory parameters for the sensitivity analysis

\begin{tabular}{ccc}
\hline Parameter & Meaning & Values \\
\hline$b_{0}$ & Initial bonding & $0,1,4,8,64$ \\
$h_{1}$ & Debondig rate & $0,3,9,18$ \\
$e_{0}$ & Void ratio & $0.75,1.50$ \\
$R$ & Overconsolidation ratio & $0.1^{\mathrm{a}}, 0.5^{\mathrm{a}}, 1,4,8,16$ \\
\hline
\end{tabular}

${ }^{\text {a }}$ States allowed by bonding

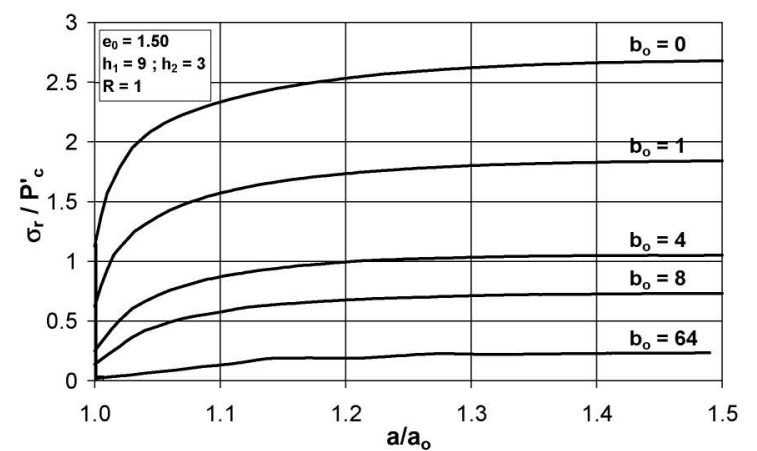

(a)

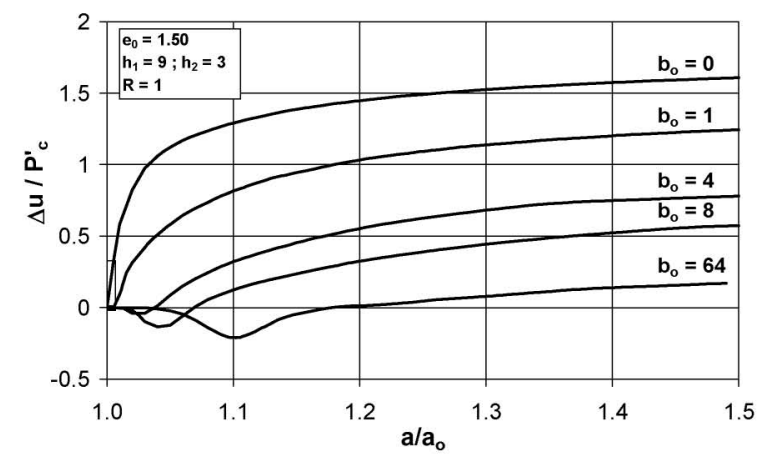

(c) ed soil behaviour. Values for the fixed parameters and ranges for the exploring parameters are coherent with those suggested from the calibration described above. The value $R$ stands for the mechanical isotropic overconsolidation ratio, $P_{\mathrm{s}}^{\prime} / p_{0}^{\prime}$, which, for bonded soils, may attain values well below 1 . Note that the initial in situ mean effective stress, $p_{0}^{\prime}$, is thus indirectly specified through the following relation

$$
p_{0}^{\prime}=\exp \left(\frac{\mathrm{N}-v_{0}}{\lambda}\right) R^{-\Lambda}
$$

Figure 6 shows the normalised load and pore pressure at the cavity for a debonding rate of $h_{1}=9$ and variable initial bonding conditions. The material is normally consolidated $(R=1)$ and the initial conditions are $p_{0}^{\prime}=12 \mathrm{kPa}$ and $e_{0}=1.50$. Two normalizations are shown, one by the initial isotropic yield pressure, $P_{c 0}^{\prime}$, and the other by the initial in situ pressure, $p_{0}^{\prime}$. The $P_{c 0}^{\prime}$ value, increasing with bonding, is a proxy for the available initial strength of the soil, analogous to the triaxial undrained shear strength that is commonly employed for similar purposes when studying unbonded soils ( $\mathrm{Yu}$ and Collins, 1998). Note that a normalization using $\left(\sigma_{\mathrm{r}}-P_{\mathrm{c} 0}^{\prime}\right) / P_{\mathrm{c} 0}^{\prime}$, would become negative for highly bonded soils; $\sigma_{\mathrm{r}}$ is the total radial pressure at the cavity wall.

Increased bonding results, as expected, in an increasing limit pressure, (Fig. 6(b)) but the extra initial strength given by bonding has diminishing returns in terms of limit pressure (Fig. 6(a)). Small amounts of bonding

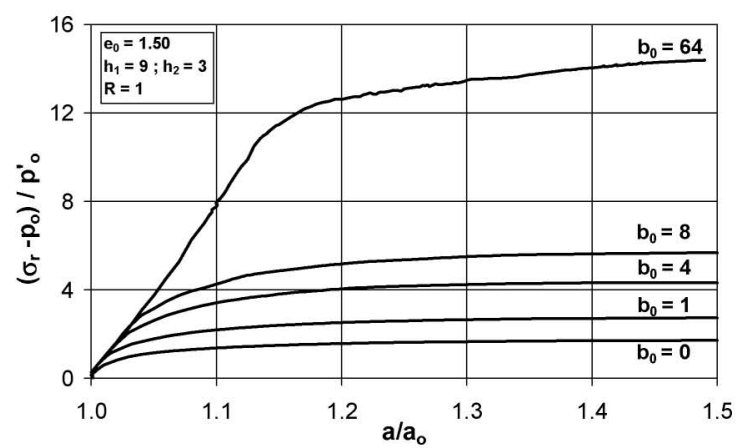

(b)

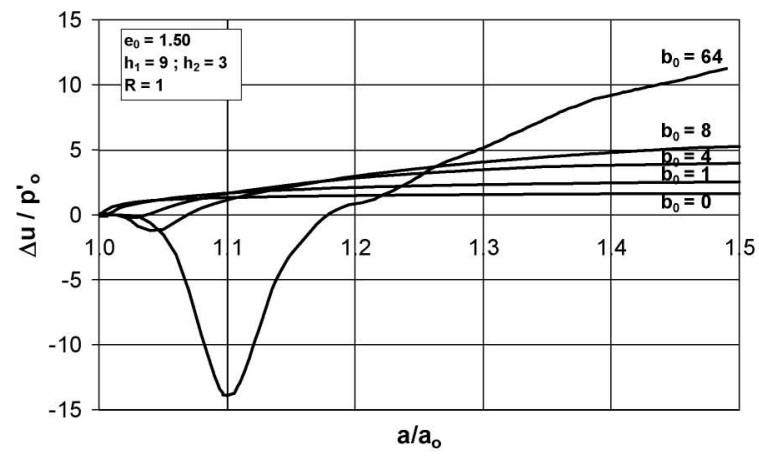

(d)

Fig. 6. Influence of initial bonding on the cavity expansion curves, (a) cavity pressure normalized by initial isotropic yield pressure, (b) cavity pressure normalized by initial in situ pressure, (c) excess pore pressure normalized by initial isotropic yield pressure and (d) excess pore pressure normalized by initial in situ pressure 


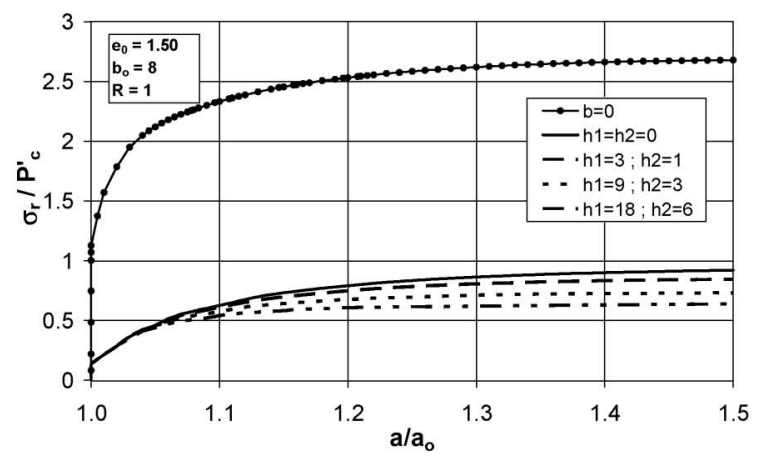

(a)

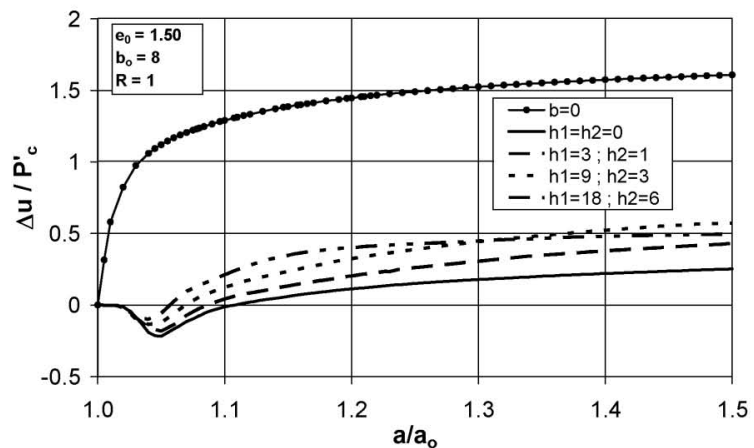

(c)

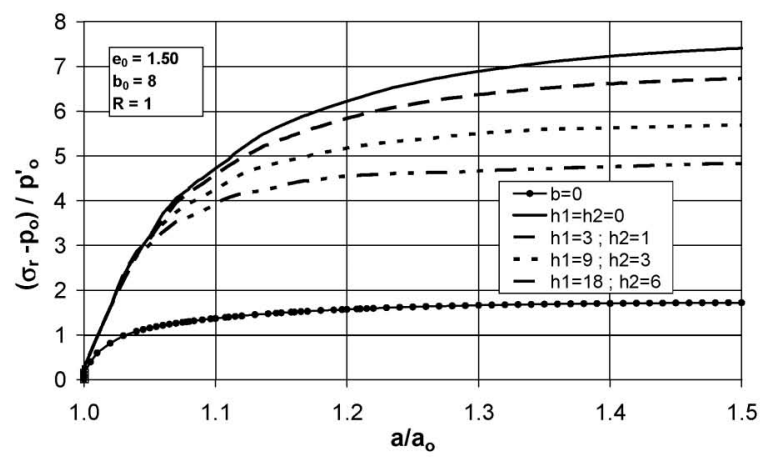

(b)

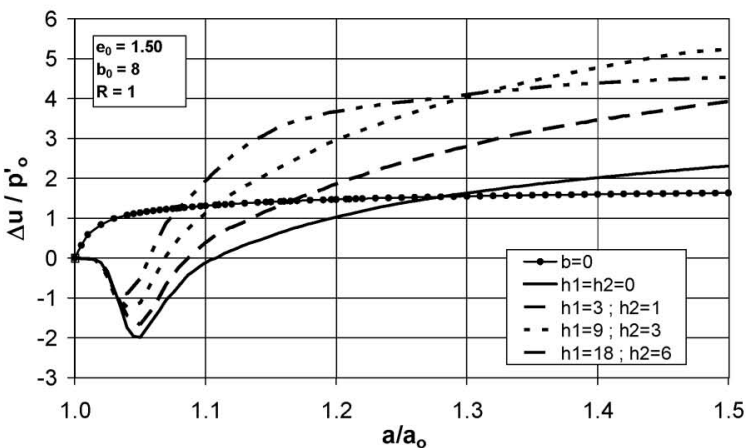

(d)

Fig. 7. Influence of debonding rate on the cavity expansion curves, (a) cavity pressure normalized by initial isotropic yield pressure, (b) cavity pressure normalized by initial in situ pressure, (c) excess pore pressure normalized by initial isotropic yield pressure and (d) excess pore pressure normalized by initial in situ pressure

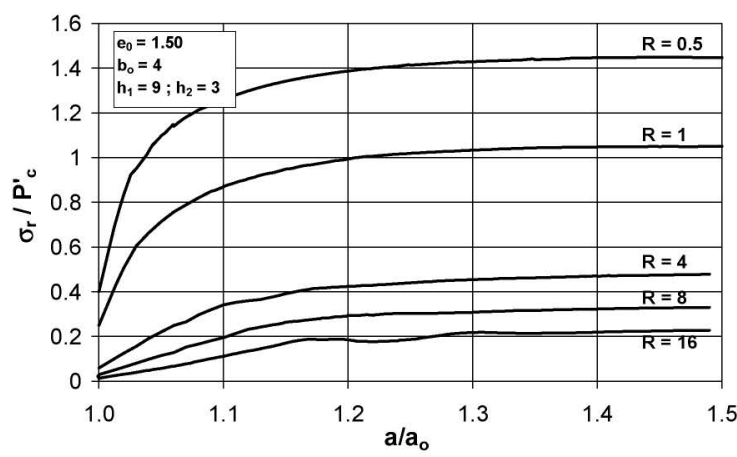

(a)

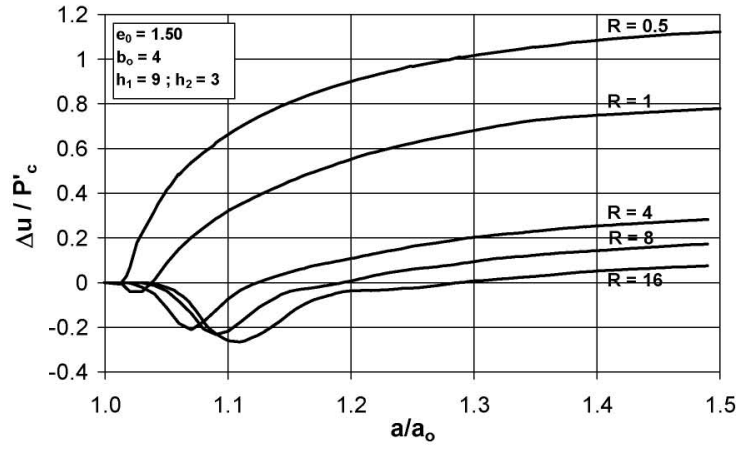

(c)

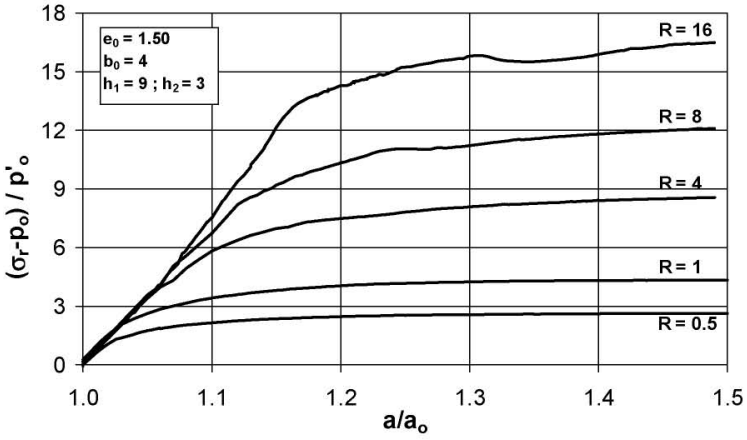

(b)

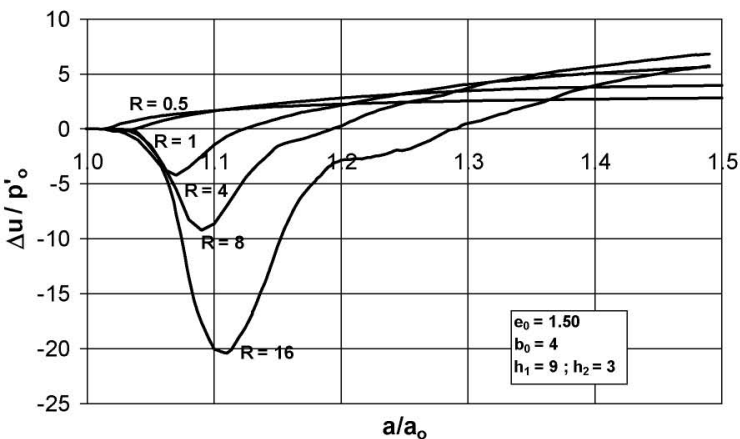

(d)

Fig. 8. Influence of mechanical overconsolidation rate on the cavity expansion curves, (a) cavity pressure normalized by initial isotropic yield pressure, (b) cavity pressure normalized by initial in situ pressure, (c) excess pore pressure normalized by initial isotropic yield pressure and (d) excess pore pressure normalized by initial in situ pressure 
result in an overall contractive response from the start, as evidenced by the increasing cavity pore pressure (Figs. 6(c) and (d)). Larger amounts of bonding will however result on a transient pore pressure decrease, indicative of a dilatant response that quickly morphs into contraction. Similar trends were observed for other sets of initial conditions.

The effect of a variable debonding rate is explored for the same set of initial conditions $\left(R=1, p_{0}^{\prime}=12 \mathrm{kPa}, e_{0}=\right.$ $1.50)$ and a fixed value of initial bonding $\left(b_{0}=8\right)$ in Fig. 7. It has some effect on the limit pressure, which decreases with an increasing debonding rate (Figs. 7(a) and (b)). But the main effect appears on the excess pore-pressure curve, where it controls the speed of switch from negative to positive (Figs. 7(c) and (d)). Similar trends were observed for other sets of initial conditions.

Within the range explored, void ratio had a lesser effect on the loading curves (Gonzalez et al., 2007). On the other hand, the effect of mechanical overconsolidation was more interesting. The effect of the isotropic mechanical overconsolidation rate, $R$, is shown in Fig 8 , for fixed $e_{0}=1.50$ and $b_{0}=4$. Increasing $R$ increases the limit pressure (Fig. 8(b)) and the negative pore pressure (Fig. 8(d)) but at a progressively inefficient rate (Figs. 8(a)-(c)).

The effects of mechanical overconsolidation, $R$, appear very similar to those due to initial bonding, $b_{0}$. The analo- gous effects of overconsolidation and bonding are made more explicit in Fig. 9, representing (for $h_{1}=18$ and $e_{0}=$ $1.5)$ the variation of limit load and excess pore pressure with $R$ and $b_{0}$. These limit values were obtained at a cavity expansion ratio $a / a_{0}=1.5$.

These results suggest that for a given pressuremeter load curve in a cemented soil, an interpreter without additional independent knowledge of ground truth would find that a variety of $R$ and $b_{0}$ combinations fit the data satisfactorily. The differing effects of overconsolidation ratio and initial bonding are difficult to resolve from the main loading curve of a single pressuremeter test. Indeed, it was easy, on view of the precedent results, to find several pairs of $R$ and $b_{0}$ showing a very similar response (Fig. $10)$.

\section{OTHER TEST PHASES}

The poor discrimination between bonding and mechanical overconsolidation achieved in the loading phase prompted the exploration of other SBPM test phases. The unloading phase of the pressuremeter test has received much attention, because, practically, it does not increase the cost of testing and it is presumably less affected by poor instrument installation than the loading curve (Shuttle and Jefferies, 1996). Also, since cycles of

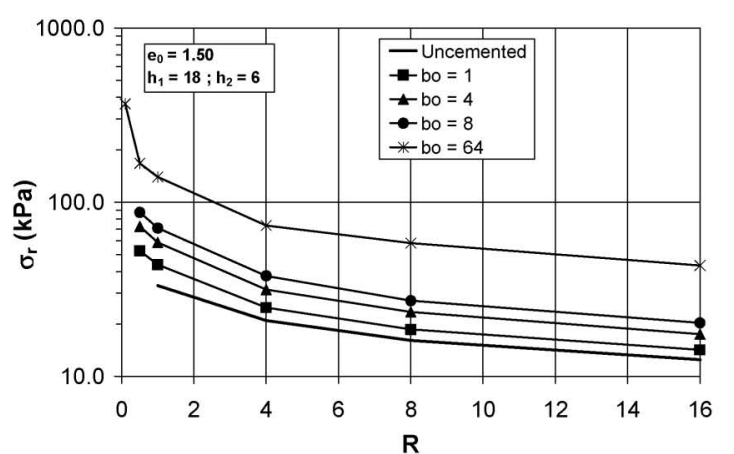

(a)

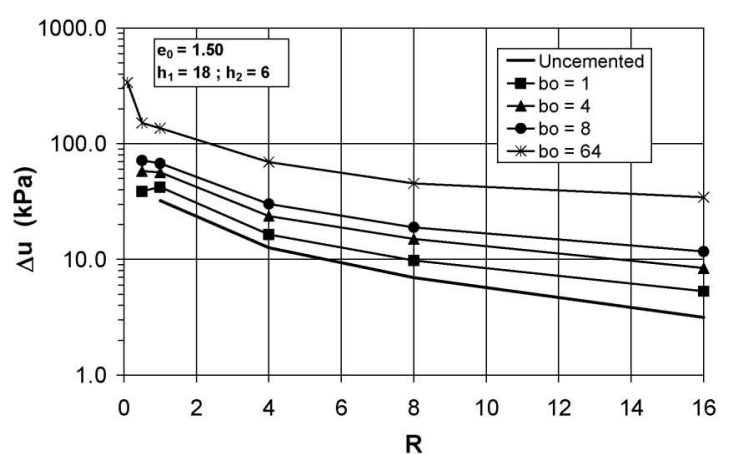

(b)

Fig. 9. Variation of load and excess pore pressure at $50 \%$ cavity strain with $R$ and $b_{0}$ for $h_{1}=18$ and $e_{0}=1.50$

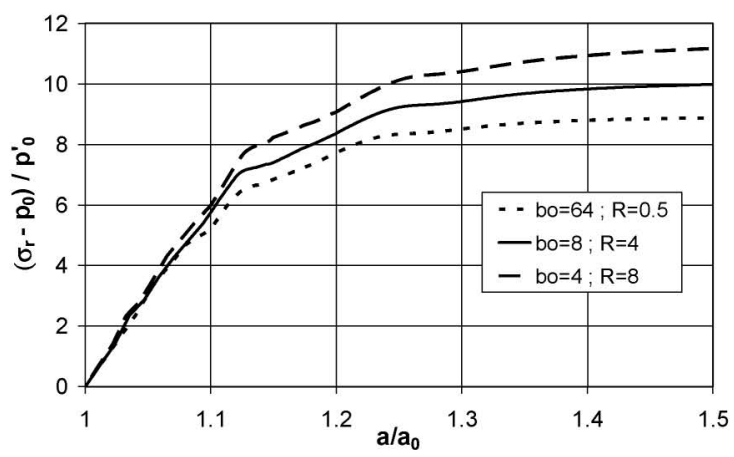

(a)

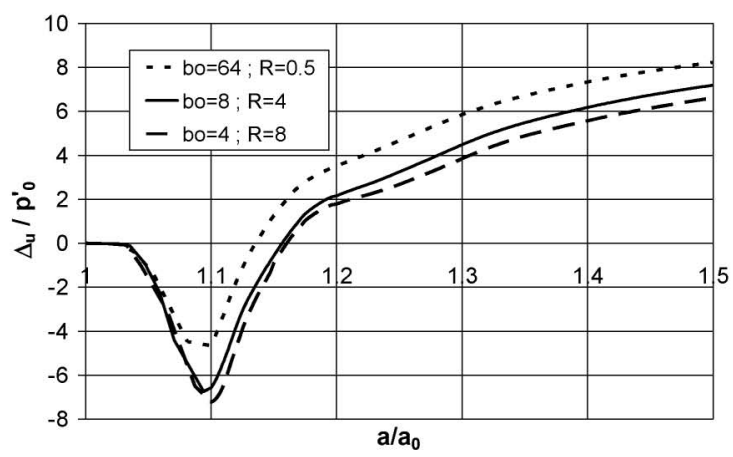

(b)

Fig. 10. Some combinations of bonding and overconsolidation ratio for a high debonding rate of $h_{1}=9$, normalised by $p_{0}^{\prime}$, (a) cavity pressure normalized by initial in situ pressure and (b) excess pore pressure normalized by initial in situ pressure 


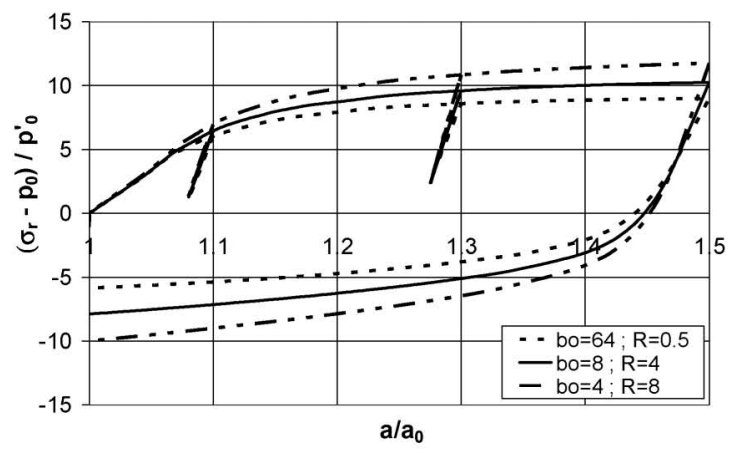

(a)

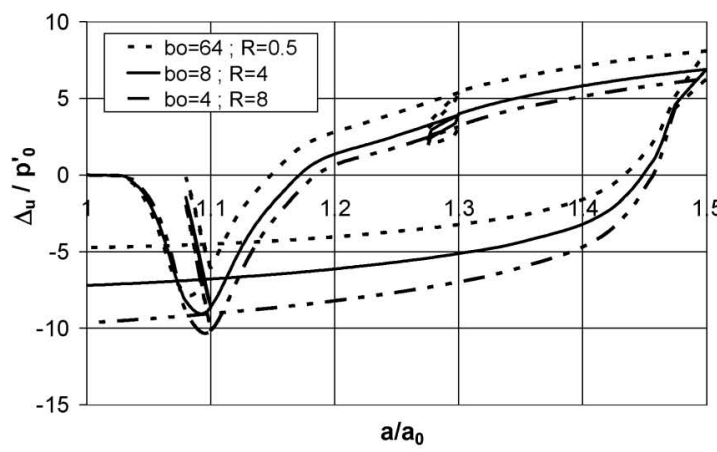

(b)

Fig. 11. Unloading and reloading for some combinations of bonding and overconsolidation ratio for $h_{1}=9$, normalised by $p_{0}^{\prime}$, (a) cavity pressure normalized by initial in situ pressure and (b) excess pore pressure normalized by initial in situ pressure

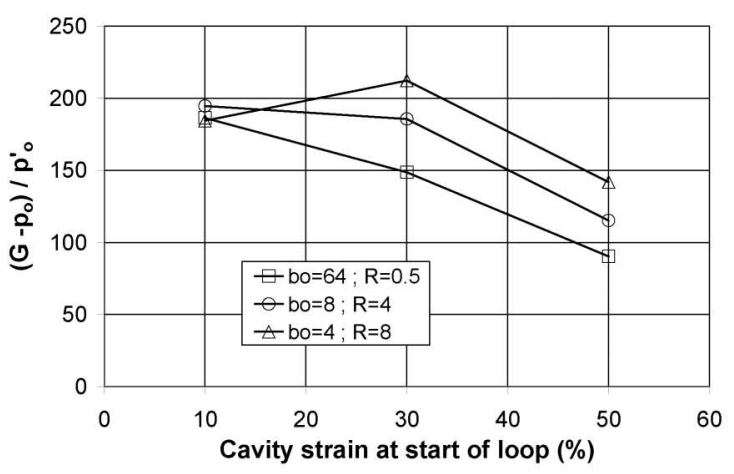

(a)

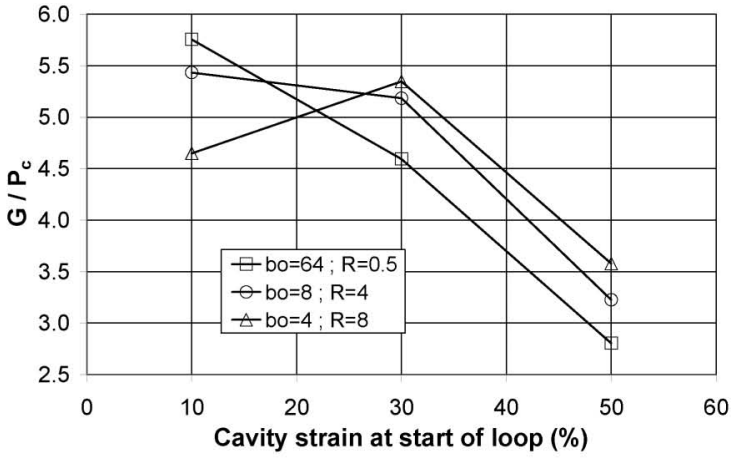

(b)

Fig. 12. Shear modulus variation with initial cavity strain, (a) normalized by initial in situ pressure and (b) normalized by initial isotropic yield pressure

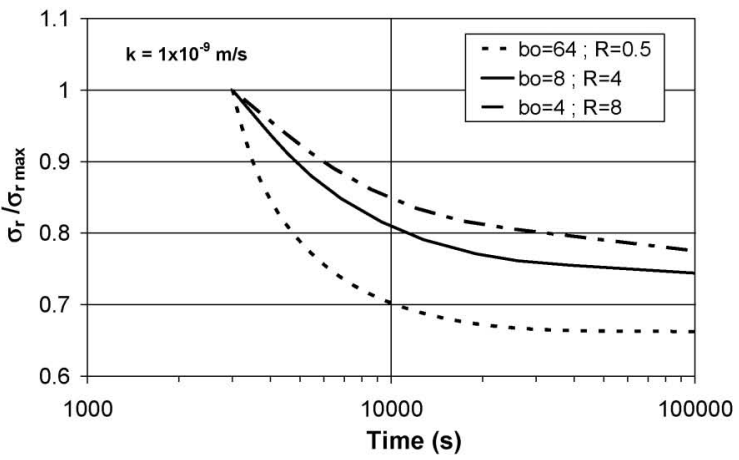

(a)

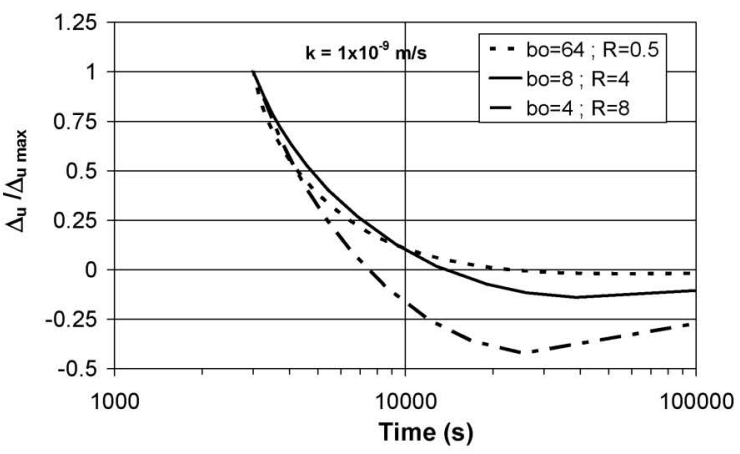

(b)

Fig. 13. Strain holding phase at $50 \%$ cavity strain for various combinations of initial bonding and mechanical overconsolidation, (a) normalized stress relaxation curve and (b) normalized pore pressure dissipation curve

unloading and reloading loops are a primary source for shear modulus data, it is common practice to carry out a few unloading-reloading cycles during the test.

Figure 11 presents the simulation of SBPM tests including two unload-reload cycles at cavity expansions of $10 \%$ and $30 \%$ respectively. The contraction or unloading curve once the cavity strain reached $50 \%$ was also simulated. The simulations was done for the three combinations of initial bonding $\left(b_{0}\right)$ and overconsolidation ratio
$(R)$ analyzed in previous section, using $h_{1}=9$ and $e_{0}=1.5$. An undrained condition and infinite length of the pressuremeter were assumed.

Differences are more apparent on the pore pressure curve than on the loading curve. It is also apparent that differences between the three cases increase with the initial unloading cavity strain. To quantify these differences, an initial secant shear moduli was derived from the simulated curves of the two unloading-reloading cycles and fi- 
nal unloading using the nonlinear approach of Bolton and Whittle (1999) as described in Yu (2004). Figure 12 shows the variation of the normalized initial secant modulus with cavity strain for the three cases explored. Substitution of mechanical overconsolidation by bonding results in smaller normalized moduli and in a clearer diminishing trend of moduli with cavity strain.

Strain-holding test phases are commonly included in SBPM tests in clay to obtain permeability-related information. However, the response observed in strain-holding phases is also dependent on the overall mechanical properties of the soil (Fioravante et al., 1994). It is thus reasonable to explore their ability to separate the effects of bonding and mechanical overconsolidation. In Fig. 13 this is made for the three parameter sets selected previously, assuming always a horizontal permeability of $1 \mathrm{E}-9$ $\mathrm{m} / \mathrm{s}$ while maintaining the infinite cavity assumption. It appears that the normalized cavity stress relaxation curve is able to discriminate significantly the effect of bonding from that of mechanical overconsolidation; increasing bonding results in increased relaxation at any time. The effects of bonding on the normalized consolidation curve are also visible though less systematic in nature.

\section{PARTIAL DRAINAGE AND FINITE SIZE EFFECTS}

There are three main sources of noise in real SBPM test results that separate them from the ideal undrained cavity analogue employed so far: imperfect installation, partial

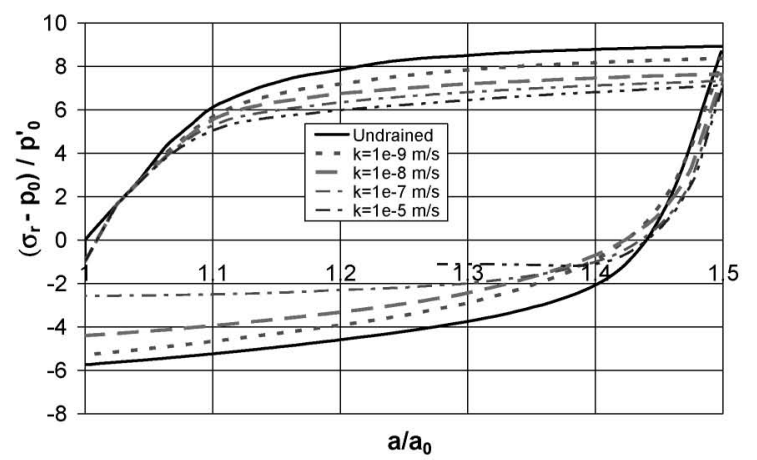

(a)

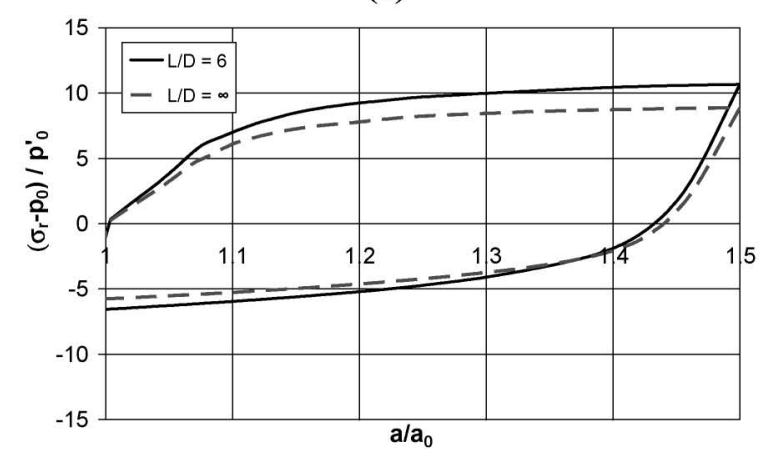

(c) drainage and the finite size of the test apparatus. In this section we numerically explore the bearing of partial drainage and finite pressuremeter length on the precedent analyses. Simulation of imperfect installation effects (e.g., over- or underexcavation) is outside the scope of this paper.

In Fig. 14, the effects of partial drainage and finite pressuremeter length on the load-unload curves are separately explored for a base case where $R=0.5, b_{0}=64$, $h_{1}=9$ and $e_{0}=1.5$. It is clear that both effects are more visible on the pore pressure curve than that on the cavity pressure curve. It is also clear that partial drainage seems

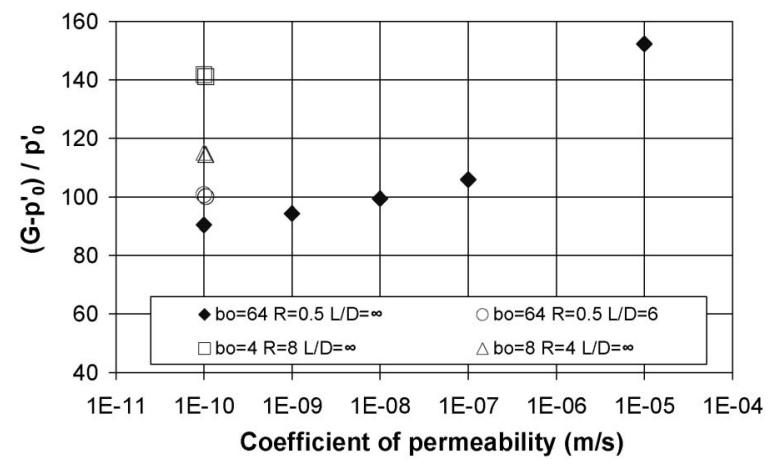

Fig. 15. Sensitivity of normalized unloading initial secant shear modulus to partial drainage, pressuremeter finite size and changing initial conditions

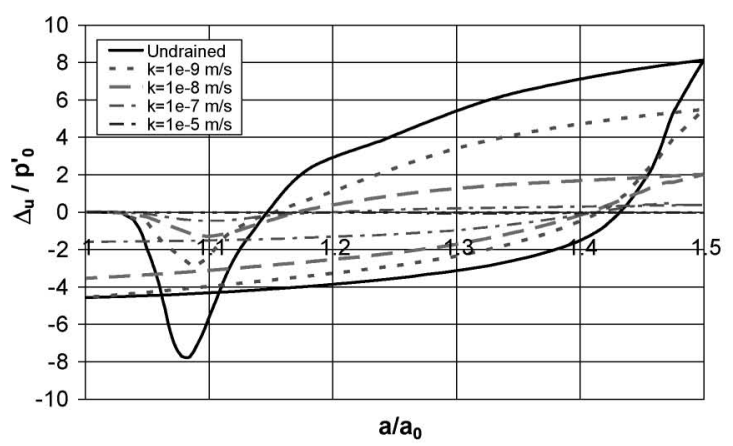

(b)

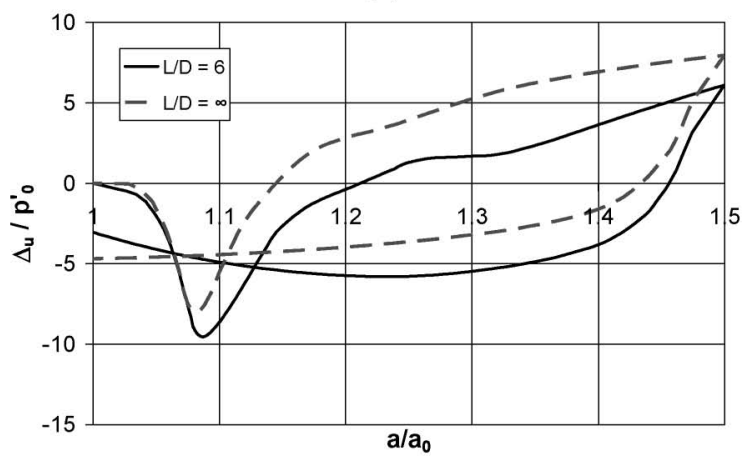

(d)

Fig. 14. SBPM load-unload curves normalized by initial in situ pressure for a case with $b_{0}=64 R=0.5$, (a) influence of partial drainage on cavity pressure for $L / D=\infty$, (b) influence of partial drainage on excess pore pressure for $L / D=\infty$, (c) influence of finite geometry on cavity pressure for $k=1 \mathrm{e}-9 \mathrm{~m} / \mathrm{s}$ and (d) influence of finite geometry on excess pore pressure for $k=1 \mathrm{e}-9 \mathrm{~m} / \mathrm{s}$ 


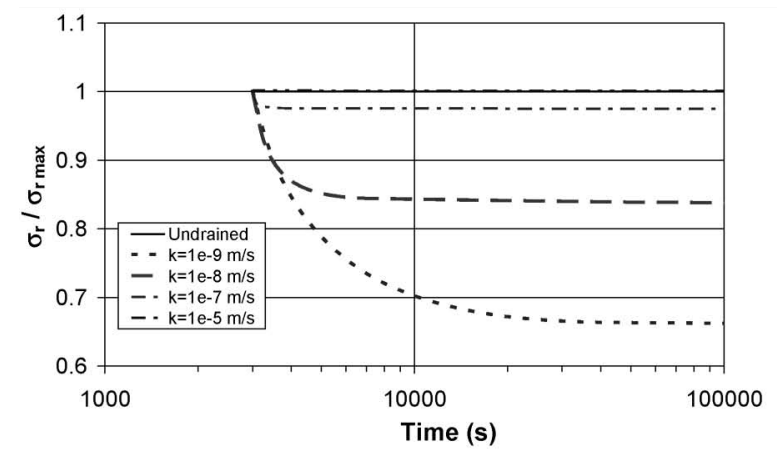

(a)

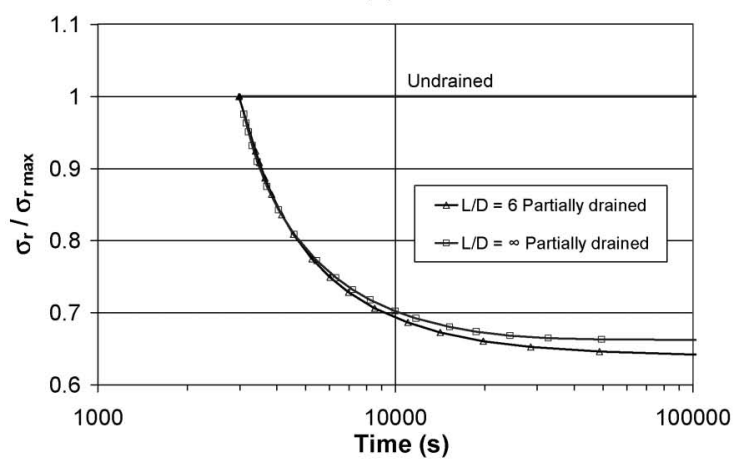

(c)

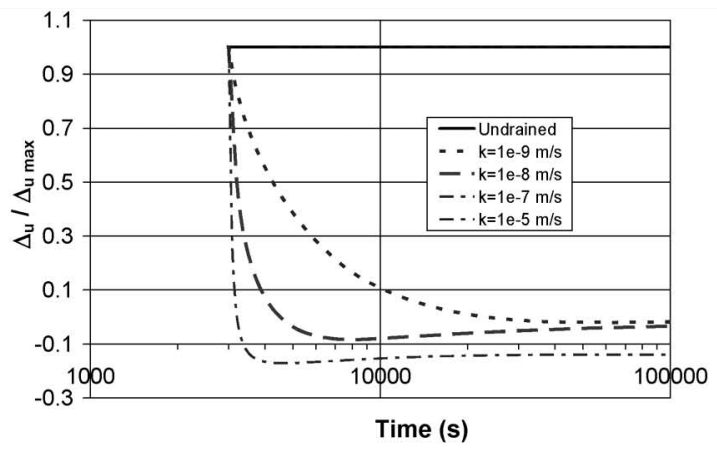

(b)

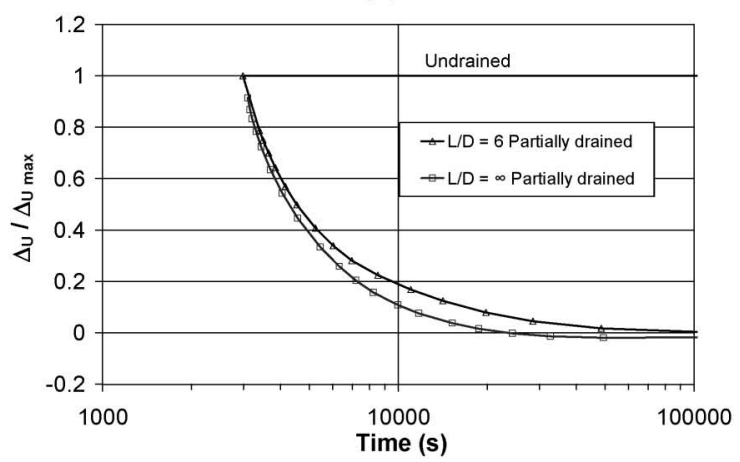

(d)

Fig. 16. Strain-holding phase for SBPM simulations with $b_{0}=64 R=0.5$, (a) influence of partial drainage on normalized stress relaxation for $L / D$ $=\infty$, (b) influence of partial drainage on normalized consolidation for $L / D=\infty$, (c) influence of finite geometry on stress relaxation for $k=$ $1 \mathrm{e}-9 \mathrm{~m} / \mathrm{s}$ and (d) influence of finite geometry on normalized consolidation for $k=1 \mathrm{e}-9 \mathrm{~m} / \mathrm{s}$

potentially more troublesome for the interpretation than the effect of finite pressuremeter length. However, as Fig. 15 makes clear, the initial secant modulus of the unloading branch is relatively more sensitive to initial bond and overconsolidation conditions than to partial drainage up to very high permeabilities. Bonding information encoded on the unloading curve may then be resilient to these types of noise.

The effects of finite pressuremeter length on the strain holding phase are moderate to small, as shown in Figs. 16(c) and (d). On the other hand, as it was to be expected, the effects on the relaxation and consolidation curves of varying the soil permeability are quite dramatic (Figs. 16(a) and (b)). However, it should be noticed that the initial slope of the normalized relaxation curve (Fig. 16(a)) is very insensitive to the permeability, whereas it responds directly to the initial bonding/OCR conditions (Fig. 13). This feature is convenient, because long holding periods are difficult to implement in practice.

\section{DISCUSSION}

In the above study we started by restricting the role of SBPM testing to just those parameters directly related to bond degradation and providing soil state information. Even with this restricted set of identification variables, the inverse problem thus posed is difficult to solve if the only input information is that given by the test loading curve. Strain holding phases and/or several unloading cy- cles seem to produce better results. Some indication of why this might happen is given by Fig. 17. The invariant deviatoric stress near the cavity experiences a large amount of softening (Fig. 17(a)). This softening results from a yield surface collapse induced by bond degradation hinted at by the stress trajectory on the triaxial plane (Fig. 17(b)). It is only when this progressive collapse is advanced that characteristic features such as pore pressure relief on unloading appear (Fig. 17(d)). It seems therefore natural that more specific bond-related information would be encoded in that part of the test. In (Fig. $17(a))$ it is also visible how the rotation of principal stresses during unload-reload cycles results in a zig-zag pattern of the invariant deviatoric stress.

Inverting the whole test curve, including reloading cycles and eventual strain-holding phases requires an intense computational effort. The work here presented opens some avenues to simplify that task. On the other hand, it is possible that a more systematic sensitivity analysis, like the one here presented for the loading phase, but directed to the unload and strain holding phases would provide approximate and simplified, yet direct, relations between structure parameters and test features, thus avoiding the need of full numerical inversions. On the other hand, the limited bearing of finite size effects on the relevant test results suggests that one-dimensional approaches may be employed with some confidence. A similar solution for bonded elasto-plastic models is then an attractive possibility to simplify the kernel of a numerical 


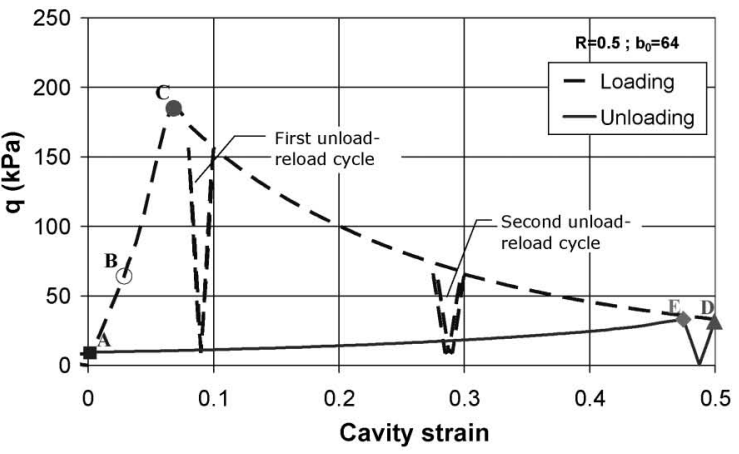

(a)

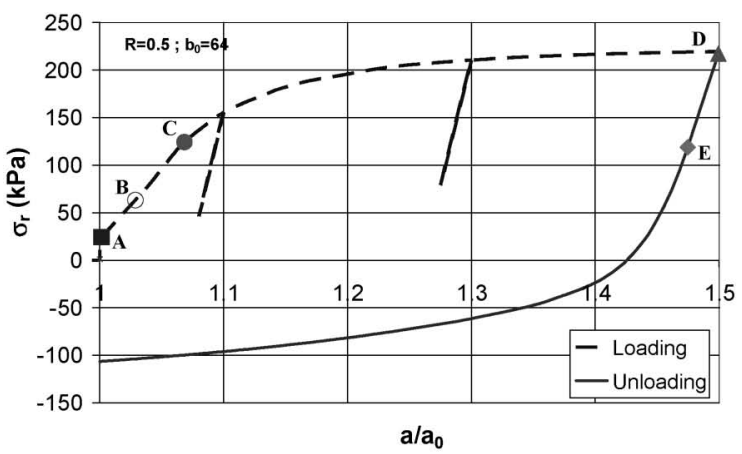

(c)

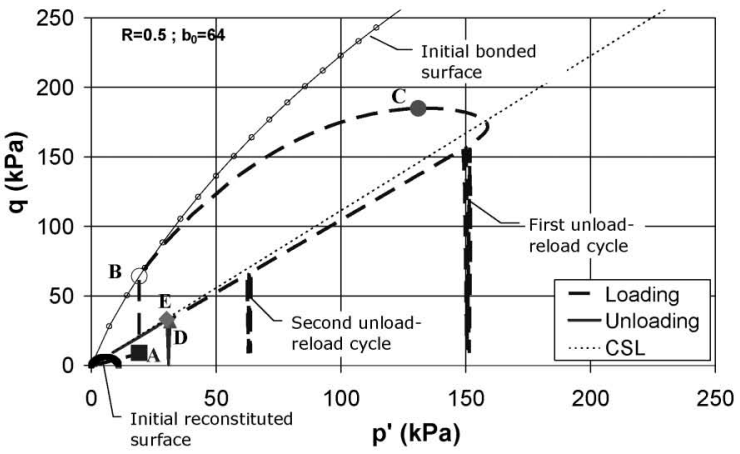

(b)

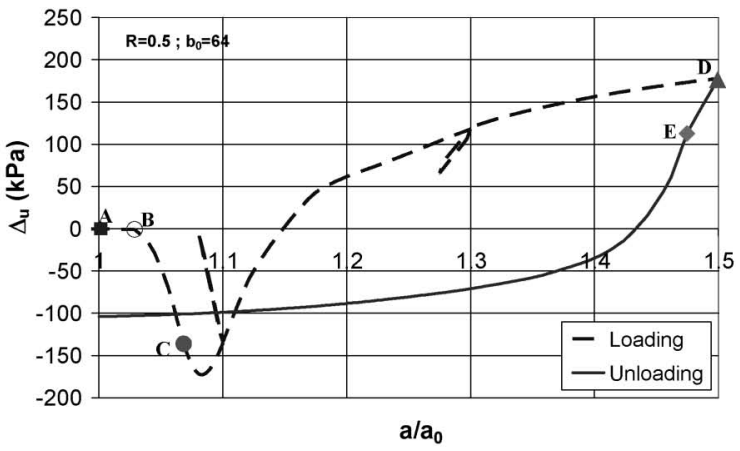

(d)

Fig. 17. Cavity analogue undrained simulations with $b_{0}=64 R=0.5 e_{0}=1.5$ with indication of singular points, (a) second stress invariant vs cavity strain, (b) effective stress path on the horizontal plane, (c) cavity pressure and (d) pore pressure

inversion procedure.

\section{CONCLUSIONS}

The SBPM might be employed to profile bond-related parameters and state variables if reconstituted soil information is independently available. Mechanical overconsolidation and initial bonding have similar effects on the loading test curves and would still make that estimation unreliable. There is a better chance to separate these two basic variables if unload-reload cycles or strain holding phases are included in the test program. The evolution of the initial unloading secant modulus with cavity strain and the initial shape of the stress relaxation curve contain unambiguous bond-related information. These two telltale features seem resistant to noise due to finite size pressuremeter effects and, to a lesser degree, partial drainage.

\section{ACKNOWLEDGEMENT}

This work was supported by the Spanish Ministry of Education trough grant 2005-05801.

\section{REFERENCES}

1) Arroyo, M., Gonzalez, N., Butlanska, J., Gens, A. and Dalton, C. (2008): SBPM testing in Bothkennar clay: structure effects, $3 r d$ International Conference on Site Characterization (ISC'3), Taipei, April 2008 (to appear).

2) Baudet, B. and Stallebrass, S. (2004): A constitutive model for structured clays, Gèotechnique, 54(4), 269-278.

3) Bolton, M. and Whittle, R. (1999): A non-linear elastic/perfectly plastic analysis for plane strain undrained expansion tests, Géotechnique, 49(1), 133-141.

4) Butterfield, R. (1979): A natural compression law for soils (an advance on $e-\log p^{\prime}$ ), Géotechnique, 29(4), 469-480.

5) Callisto, L. and Rampello, S. (2004): An interpretation of structural degradation for three natural clays, Can. Geotech. J., 41, 392-407.

6) Collins, I. F. and Yu, H. S. (1996): Undrained cavity expansions in critical state soils, Int. J. Num. An. Meth. Geomech., 20, 489-516.

7) Cotecchia, F. and Chandler, R. J. (2000): A general framework for the mechanical behaviour of clays, Géotechnique, 50(4), 431-447.

8) Fioravante, V., Jamiolkowski, M. and Lancellotta, R. (1994): An analysis of pressuremeter holding tests, Géotechnique, 44(2), 227-238.

9) Gens, A. and Nova, R. (1993): Conceptual bases for a constitutive model for bonded soils and weak rocks, Geotechnical Engineering of Hard Soils-Soft Rocks (eds. by Anagnostopoulos et al.), Balkema, 485-494.

10) Gibson, R. E. and Anderson, W. F. (1961): In situ measurement of soil properties with the pressuremeter, Civil Engng. Public Works Rev., 56, 615-618.

11) Gonzalez, N., Arroyo, M. and Gens, A. (2007): The effect of structure in pressuremeter tests in clay, Numerical Models in Geomechanics, NUMOG X (eds. by Pande \& Pietrusckzak), 721-732.

12) Jang, I., Chung, C.-K., Kim, M. and Cho, S. (2003): Numerical assessment on the consolidation characteristics of clays from strain holding, self-boring pressuremeter test, Computers and Geotechnics, 30, 121-140.

13) Kavvaddas, M. and Amorosi, A. (2000): A constitutive model for structured soils, Geotechnique, 50(3), 263-273.

14) Rangeard, D., Dano, C. and Marchina, P. (2004): Identifying soil compressibility from pressuremeter test, Numerical Models in Geomechanics, NUMOG IX (eds. by Pande \& Pietrusckzak), 683-689. 
15) Rouainia, M. and Muir Wood, D. (2000): A kinematic hardening constitutive model for natural clays with loss of structure, Géotechnique, 50(2), 153-164.

16) Sheng, D., Sloan, S. W. and Yu, H. S. (2000): Aspects of finite element implementation of critical state models, Computational Mechanics, 26, 185-196.

17) Shuttle, D. A. and Jefferies, M. G. (1996): Reliable parameters from imperfect SBP tests in clays, Proc. International Conference on Advances in Site Investigation Practice, London, 571-585.

18) $\mathrm{Yu}, \mathrm{H}$. (2004): James K. Mitchell lecture, In situ soil testing: from mechanics to interpretation, Geotechnical and Geophysical Site Characterization ISC '2 (eds. by Viana da Fonseca \& Mayne), 3-38.
19) Yu, H. S. (1998): CASM: A unified state parameter model for clay and sand, Int. J. Num. An. Meth. Geomech, (22), 621-653.

20) $\mathrm{Yu}, \mathrm{H}$. S. and Collins, I. F. (1998): Analysis of self-boring pressuremeter tests in overconsolidated clays, Géotechnique, 48(5), 689-693.

21) Yu, H. S. and Tan, S. M. (2007): A critical state model for bonded geomaterials, Numerical Models in Geomechanics, NUMOG $X$ (eds. by Pande \& Pietrusckzak), 71-77.

22) Zentar, R., Moulin, G. and Hicher, P. Y. (1998): Numerical analysis of pressuremeter test in soil, 4th European Conference on $\mathrm{Nu}$ merical Methods in Geomechanics (NUMGE), Udine, 593-600. 